\title{
C-ANCA positivity in a Belgian patient with pulmonary paracoccidioidomycosis
}

\author{
I. Stappaerts*, J. Bogers**, D. Ebo+, E. Vanden Broecke++, W.J. Stevens+, P. Vermeire*
}

c-ANCA positivity in a Belgian patient with pulmonary paracoccidioidomycosis. I. Stappaerts, J. Bogers, D. Ebo, E. Vanden Broecke, W.J. Stevens, P. Vermeire. (CERS Journals Ltd 1997.

ABSTRACT: We present the case of a $69 \mathrm{yr}$ old, white male, suffering from diffuse interstitial lung disease, finally diagnosed as paracoccidioidomycosis or South American blastomycosis. During the course of his disease, antineutrophil cytoplasmic antibodies (c-ANCAs) became positive, suggesting the possibility of a Wegener's granulomatosis.

Transbronchial biopsies and a video-assisted thoracoscopic lung biopsy revealed only the pulmonary yeast infection, without other co-existing pathology. During treatment with itraconazole, the patient improved clinically and functionally, and c-ANCAs became negative. Serological monitoring confirmed the diagnosis.

To our knowledge, this is the first report describing positive c-ANCAs in a patient with paracoccidioidomycosis. It re-emphasizes the fact that cautious interpretation of c-ANCAs in patients without convincing clinical signs or pathological evidence of a granulomatous vasculitis is absolutely necessary. In this era of increased mobility, a thorough medical history, including documentation of travel, remains an inexpensive tool in making a diagnosis and is still the cornerstone of good medical practice.

Eur Respir J 1997; 10: 2419-2422.
Depts of *Respiratory Medicine, **Pathology, +Immunology and Rheumatology, University Hospital Antwerp, Edegem, Belgium. ${ }^{++}$Dept of Respiratory Medicine, St. Jozef General Hospital, Mortsel, Belgium.

Correspondence: I. Stappaerts

Respiratory Medicine

University Hospital Antwerp

Wilrijkstraat 10

2650 Edegem

Belgium

Keywords: antineutrophil cytoplasmic antibodies

interstitial lung disease

paracoccidioidomycosis

Received: October 211996

Accepted after revision May 61997

\section{Case report}

A $69 \mathrm{yr}$ old, white male, who underwent coronary artery bypass surgery in 1983 , presented with a history of progressive dyspnoea on exertion, chest tightness and a nonproductive cough of 4 month duration. Previous treatment with erythromycin had not improved symptoms. He had a smoking history of 45 pack-years.

From 1948 to 1963, the patient worked on a plantation in Paraguay and travelled in Brasil and Argentina. Afterwards, he worked as a representative for laboratory equipment in Belgium. He denied asbestos exposure. His medication consisted of dipyridamole and acetylsalicylic acid.

Physical examination was completely normal. Chest radiography and computed tomography $(\mathrm{CT})$ of the thorax revealed diffuse alveolar filling and a reticulonodular interstitial pattern (fig. 1). Laboratory examination only demonstrated a polyclonal hypergammaglobulinaemia. Pulmonary function tests showed a moderately restrictive ventilatory pattern, with a vital capacity (VC) of $2.2 \mathrm{~L}$ ( $61 \%$ of predicted value), a forced expiratory volume in one second (FEV1) of $1.7 \mathrm{~L}$ (61\% pred), a total lung capacity (TLC) of $4.8 \mathrm{~L}$ (74\% pred), and an abnormal carbon monoxide transfer factor $(T \mathrm{~L}, \mathrm{CO})$ of $40 \%$ pred. There was a mild hypoxaemia, with an arterial oxygen tension $\left(\mathrm{Pa}_{\mathrm{a}} \mathrm{O}_{2}\right)$ of $9.6 \mathrm{kPa}$. Bronchoscopy showed no endobronchial abnormalities. Cultures of bronchoalveolar lavage fluid remained sterile and a cell count revealed elevated numbers of lymphocytes (21\%), eosinophils (4.5\%) and neutrophils (6.5\%). The CD4/CD8 ratio was normal. Transbronchial biopsies in the left lower lobe showed normal alveolar tissue.

In the absence of a clear diagnosis, empirical therapy with methylprednisolone at a dose of $1 \mathrm{mg} \cdot \mathrm{kg}^{-1}$ was initiated. After initial clinical, radiological and lung functional improvement, the patient was hospitalized because of severe dyspnoea and temperature up to $39^{\circ} \mathrm{C}$, not responsive to amoxycillin-clavulanate. At that time, the patient was receiving $24 \mathrm{mg}$ methylprednisolone. On admission, we saw a sick, apathetic patient with severe muscular atrophy. Chest radiography again revealed diffuse alveolar infiltrates. Laboratory analysis showed an inflammatory pattern (erythrocyte sedimentation rate

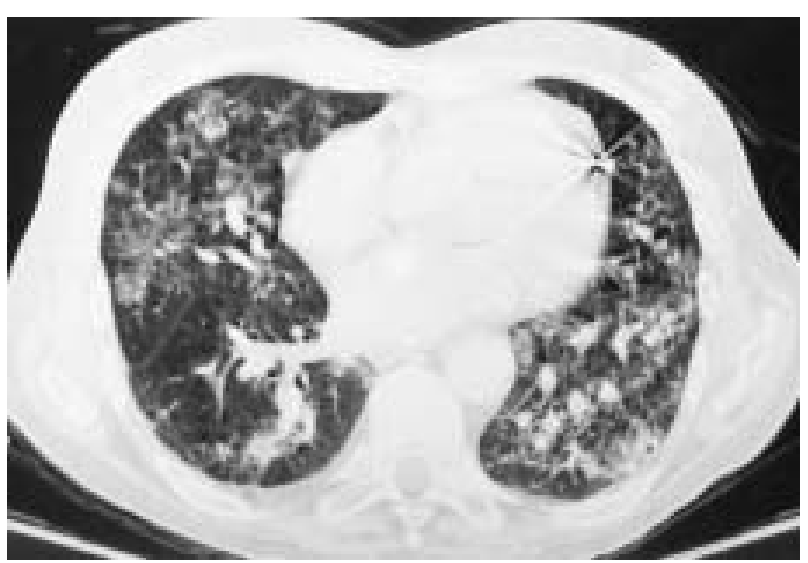

Fig. 1. - Computed tomography (CT) scan of the thorax showing diffuse filling and a reticulonodular interstitial pattern. 
(ESR) $91 \mathrm{~mm} \cdot \mathrm{h}^{-1}, \mathrm{C}$-reactive protein $5.2 \mathrm{mg} \cdot \mathrm{dL}^{-1}$ ), and antineutrophil cytoplasmic antibodies (c-ANCAs) were detectable in a low titre of 1/40 with the indirect immunofluorescent (IIF) antibody test. Pulmonary restriction again reached the previous values and hypoxaemia had deteriorated $\left(\mathrm{Pa}, \mathrm{O}_{2} 8.7 \mathrm{kPa}\right)$. Urine sediment was normal and proteinuria was absent.

Another bronchoscopy was performed and lavage fluid showed $43 \%$ lymphocytes. Grocott staining on transbronchial biopsies established the diagnosis of a pulmonary yeast infection, identified on bronchial aspirate as Paracoccidioides brasiliensis (fig. 2). Cultures on a sabouraud-dextrose medium remained negative after 1 month. A blood sample was sent to the Centers for Disease Control and Prevention (CDC) in Atlanta for serological confirmation. The complement fixation (CF) test was positive for paracoccidioidomycosis (titre of 1/64). The agar gel test showed one band of precipitins. Human immunodeficiency virus (HIV)-1 and HIV-2 serology was negative.

Itraconazole was initiated at a dose of $400 \mathrm{mg}$ daily, while methylprednisolone therapy was gradually tapered and stopped. However, despite receiving itraconazole for 3 weeks, the patient remained ill and fever intermittently relapsed up to $39^{\circ} \mathrm{C}$. Meanwhile, c-ANCA titre rose to $1 / 80$. Therefore, Wegener's granulomatosis and associated vasculitides were included in the differential diagnosis and, in order to exclude such an underlying disease, a video-assisted thoracoscopic lung biopsy was finally performed. A biopsy of $3.7 \times 2.2 \times 0.4$ $\mathrm{cm}$ was taken in the right lower lobe. Microscopy showed alveoli filled with histiocytes, inflammatory cells and giant cells amidst globular yeasts (Grocott staining), showing the typical "multiple budding" aspect of $P$. brasiliensis. There were no signs of vasculitis. Ultrastructural investigation of the lung tissue revealed small free fungal cells ranging $2-3 \mu \mathrm{m}$ in diameter, probably representing detached buds. Inside the fungi, remnants of mycotic organelles could be distinguished

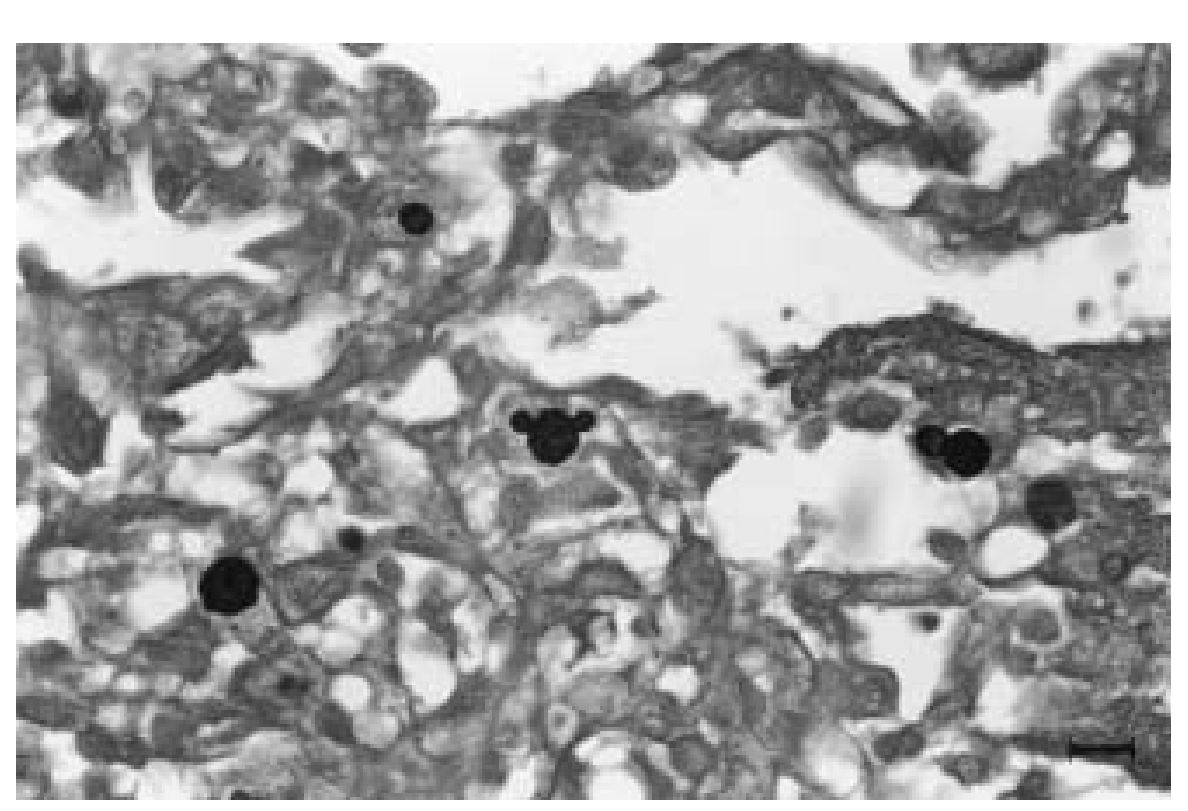

Fig. 2. - Compressed lung tissue showing yeast-like cells of Paracoccidiomycosis brasiliensis clearly demonstrating small pinched-off buds and multiple scars from detached blastospores. (Grocott stain; internal scale bar $=35 \mu \mathrm{m}$ ). surrounded by a thick, uniform, amorphous capsule. Sporulation could not be documented. Ear, nose, and throat (ENT) examination, CT of the brain, and abdominal echography were normal. Evaluation of adrenal function revealed a partial primary insufficiency by means of an elevated level of basal adrenocorticotrophic hormone (ACTH) and absence of adrenal reactivity after tetracosactide stimulation. Substitution with $20 \mathrm{mg}$ hydrocortisone daily was initiated. The itraconazole plasma level was monitored and proved to be therapeutic.

Eleven months later, the patient was doing well. Inflammatory parameters had normalized completely and results of pulmonary function tests had stabilized, showing a permanent restriction (VC 2.3 L, FEV1 1.8 L, TLC $4.6 \mathrm{~L}$, TL,CO $31 \%$ pred). Chest radiography showed bilateral interstitial scarring. Itraconazole treatment was stopped after 7 months. In order to specify the ANCA positivity, an enzyme-linked immunosorbent assay (ELISA) was performed with the ANCA profile ELISA (immunoglobulin G (IgG)) kit (Euroimmun, Groß Grönau, Germany), which detects antibodies to myeloperoxidase, proteinase-3, lactoferrin, elastase, cathepsin G and lysozyme. The patient's serum was negative to all these enzymes. Meanwhile c-ANCAs and the CF test had become negative (titre $1 / 8$ ), and precipitins for $P$. brasiliensis had disappeared.

\section{Discussion}

Paracoccidioidomycosis or South American blastomycosis, caused by the dimorphic fungus $P$. brasiliensis, is one of the most common endemic mycoses in Latin America. The disease can be found from Mexico $\left(20^{\circ} \mathrm{N}\right)$ to Argentina $\left(35^{\circ} \mathrm{S}\right)$. Infection is probably acquired by inhalation.

In immunocompetent individuals, primary infection usually occurs subclinically. Failure to develop a good cellular immune response, however, can cause progressive haematogenous dissemination. More frequently, paracoccidioidomycosis presents as a chronic pulmonary or disseminated disease. Pulmonary lesions can evolve to extensive fibrosis after cure [1-3]. Latent infection may be present in untreated primary or residual lesions of chronic forms. As in the present patient, a very long time period can elapse between departure from the endemic region and the first disease manifestations [4].

Microscopic demonstration of the fungus in sputum, bronchoalveolar lavage fluid or tissue biopsies is diagnostic $[1,2,5]$. Serological tests, especially complement fixation and immunodiffusion, are useful both for diagnosis and evaluation of response to treatment $[1,2,6]$. Imidazole derivatives, in particular itraconazole $(100 \mathrm{mg}$ daily for 6 months), appear to be the first choice treatment $[1,2,7,8]$. 
The pulmonary manifestations in the present patient probably represent a late reactivation that was aggravated by the inappropriate use of an immunosuppressive dose of methylprednisolone. Performing a thoracoscopic lung biopsy after the diagnostic failure of the initial bronchoscopy would have been more accurate. Even after the diagnosis of paracoccidioidomycosis was made on the second bronchoscopy, uncertainty about the possibility of another underlying disease persisted, especially when the c-ANCA titre was seen to rise.

Over the last decade, c-ANCAs have emerged as sensitive and highly specific markers for vasculitis. The relationship between c-ANCA (usually antiproteinase-3) and Wegener's granulomatosis is indeed among the most disease-specific relationships observed in human autoimmune serology, with a specificity exceeding 90$95 \%$ in most studies $[9,10]$. In the appropriate clinical setting, a positive c-ANCA result on IIF, in which staining of the cytoplasm in ethanol-fixed neutrophils is coarse and granular, strongly supports the diagnosis of Wegener's granulomatosis. Specificity, however, is not absolute. In the first place, although it is infrequent, c-ANCAs are found in vasculitides closely related to Wegener's granulomatosis, such as microscopic polyangiitis, ChurgStrauss syndrome, classic polyarteritis nodosa [10], and, very exceptionally, in other forms of vasculitis, including Takayasu arteritis and giant cell arteritis [11, 12]. Secondly, c-ANCAs have been reported in rheumatoid arthritis and other connective tissue diseases, such as systemic lupus erythematosus [13]. Finally, and most importantly, additional doubt as to the specificity of cANCAs has arisen from reports of c-ANCA-positivity in patients with infection. Indeed, though in general absent in infectious disorders [14, 15], low titres of cANCA have been observed in HIV infection [16], tuberculosis [17, 18], and invasive amoebiasis [19]. DAVENPORT et al. [20], in a retrospective analysis, found 19 positive c-ANCA results in 266 patients with upper or lower respiratory tract symptoms who did not have Wegener's granulomatosis. Eleven of these patients suffered from a respiratory tract infection.

In the present patient, the clinical picture of fever, general malaise with pulmonary infiltrates (unresponsive to antibiotic and antimycotic treatment), together with the occurrence of a c-ANCA, suggested the diagnosis of Wegener's granulomatosis. However, by performing a thoracoscopic lung biopsy, it was possible to confirm our initial diagnosis of paracoccidioidomycosis and to exclude vasculitis. Itraconazole was continued, resulting in clinical recovery associated with the c-ANCA immunofluorescence becoming negative.

We would, therefore, like to add this patient with paracoccidioidomycosis to the list of c-ANCA-associated infections. The negative ELISA for proteinase-3 and myeloperoxidase, lactoferrin, elastase, cathepsin $G$ and lysozyme might indicate the presence of a hitherto unknown antigen or an antigen not identified by this test kit (e.g. antibactericidal/permeability-increasing protein [21]). Today, there is no firm evidence that microorganisms can induce ANCA synthesis. However, the demonstration of proteinase- 3 expression on the cell surface of activated neutrophils in patients with sepsis [22], and the release of proteinase-3 upon neutrophil degranulation in patients suffering from sepsis and pneumonia [23], provide possible mechanisms for the induction of c-ANCA production.

In conclusion, we present a case of antineutrophil cytoplasmic antibody positivity in a patient with a, probably steroid-enhanced, adult type of paracoccidioidomycosis, in whom excluding a antineutrophil cytoplasmic antibody-associated vasculitis was of paramount importance, because of the completely different therapeutic approach.

Acknowledgement: The authors wish to thank Biognost, Wevelgem, Belgium for providing the Euroimmun ANCA Profile ELISA kit.

\section{References}

1. Taborda A, Arechavala AI. Paracoccidioidomycosis. In: Sarosi GA, Davies SF, eds. Fungal Diseases of the Lung. New York, Raven Press, 1993; pp. 85-94.

2. Rios-Fabra A, Restrepo Moreno A, Isturiz RE. Fungal infection in Latin American countries. Infect Dis Clin North Am 1994; 8: 141-145.

3. Colombo AL, Faiçal S, Kater CE. Systematic evaluation of the adrenocortical function in patients with paracoccidioidomycosis. Mycopathologia 1994; 127: 89-93.

4. Brummer E, Castañeda E, Restrepo A. Paracoccidioidomycosis: an update. Clin Microbiol Rev 1993; 62: 89-117.

5. Iwama de Mattos MCF, Mendes RP, Marcondes-Machado $\mathrm{J}$, et al. Sputum cytology in the diagnosis of pulmonary paracoccidioidomycosis. Mycopathologia 1991; 114: 187-191.

6. Del Negro GMB, Garcia NM, Rodrigues EG, et al. The sensitivity, specificity and efficiency values of some serological tests used in the diagnosis of paracoccidioidomycosis. Rev Inst Med Trop São Paulo 1991; 33: 277-280.

7. Naranjo MS, Trujillo M, Munera MI, Restrepo P, Gomez I, Restrepo A. Treatment of paracoccidioidomycosis with itraconazole. J Med Vet Mycol 1990; 28 : 67-76.

8. Restrepo A. Treatment of tropical mycosis. J Am Acad Dermatol 1994; 31: S91-S93.

9. Gross WL, Schmitt WH, Csernock E. Antineutrophil cytoplasmic autoantibody-associated diseases: a rheumatologist's perspective. Am J Kidney Dis 1991; 18: 175-179.

10. Gross WL, Schmitt WH, Csernock E. ANCA and associated diseases: immunodiagnostic and pathogenetic aspects. Clin Exp Immunol 1993; 91: 1-12.

11. McHugh NJ, James IE, Plant GT. Anticardiolipin and antineutrophil antibodies in giant cell arthritis. J Rheumatol 1990; 17: 916-922.

12. Kerr GS, Fleisher TA, Hallahan CW, Leavitt RY, Fauci AS, Hoffman GS. Limited prognostic value of changes in antineutrophil cytoplasmic antibody titer in patients with Wegener's granulomatosis. Arthritis Rheum 1993; 36: 365-371.

13. Savige JA, Gallicchio MC, Stockman A, et al. Antineutrophil cytoplasmic antibodies in rheumatoid arthritis. Clin Exp Immunol 1991; 86: 92-98.

14. Schmitt WH, Csernock E, Gross WL. ANCA and infection. Lancet 1991; 337: 1416-1417.

15. Murphy EA, McVie A, Galbraith I, Capell HA. Antineutrophil cytoplasmic antibody titres in patients with recent infection (letter). Br J Rheumatol 1993; 32: 84. 
16. Klaassen RJL, Goldschmeding R, Dolman KM, et al. Antineutrophil cytoplasmic autoantibodies in patients with symptomatic HIV infection. Clin Exp Immunol 1992; 87: 24-30.

17. De Clerck LS, Van Offel JF, Smolders WA, et al. Pitfalls with antineutrophil cytoplasmic antibodies (ANCA). Clin Rheumatol 1989; 8: 512-516.

18. Adebajo AO, Charles P, Hazleman BL, Maini RN. Antineutrophil cytoplasmic antibody titres in patients with recent infection. Br J Rheumatol 1993; 32: 941-942.

19. Pudifin D, Duursma J, Garhiram V, Jackson T. Invasive amoebiasis is associated with the development of antineutrophil cytoplasmic antibody. Clin Exp Immunol 1994; 97: 48-51.

20. Davenport A, Lock RJ, Wallington TB. Clinical relevance of testing for antineutrophil cytoplasm antibodies
(ANCA) with a standard indirect immunofluorescence ANCA test in patients with upper or lower respiratory tract symptoms. Thorax 1994; 49: 213-217.

21. Yang JJ, Tuttle R, Falk RJ, Jennett JC. Frequencies of antibactericidal permeability-increasing protein (BPI) and anti-azurodin in patients with renal disease. Clin Exp Immunol 1996; 105: 125-131.

22. Csernok E, Schmitt WH, Ernst M, Bainton D, Gross WL. Membrane surface proteinase 3 expression and intracytoplasmic immunoglobulin on neutrophil from patients with ANCA-associated vasculitides. Adv Exp Med Biol 1993; 336: 45-50.

23. Henshaw TJ, Malone CC, Gabay JE, Williams RC. Elevations of neutrophil proteinase-3 in serum of patients with Wegener's granulomatosis and polyarteritis nodosa. Arthritis Rheum 1994; 37: 104-107. 